\title{
A New Composite Restorative Based on a Hydrophobic Matrix
}

\author{
W. H. DOUGLAS, R. G. CRAIG, and C. J. CHEN
}

Department of Dental Materials, School of Dentistry, The University of Michigan, Ann Arbor, Michigan 48109

A hydrophobic restorative composite based on a fluorocarbon analog of an alkyl methacrylate and a bisphenol adduct was formulated into a onepaste system, which polymerized in the presence of blue light. Physical, mechanical, and waterrelated properties were determined. High contact angles and low water sorption were shown by the experimental composite. Capillary penetration of oral fluids around restorations, therefore, could be prevented in the presence of this highly hydrophobic surface. The physical and mechanical properties of the experimental composite were either comparable to or somewhat less favorable than commercial Bis-GMA composites.

\section{J Dent Res 58(10):1981-1986, October 1979}

\section{Introduction.}

The majority of current commercial composite restorative systems are based on Bis-GMA and consist of $70-80 \%$ by weight of silanated inorganic materials., ${ }^{1,2}$ It has been shown that these composite materials have substantially improved physical and mechanical properties compared to unfilled acrylic materials. ${ }^{3-10}$ However, a major problem with unfilled acrylics and composites is the penetration of oral fluids via microleakage through capillary spaces between the restoration and the tooth. ${ }^{1-13}$ These fluids contain bacteria which can cause decay beneath the filling.

The driving force for the capillary penetration of a liquid between two solids has been shown by O'Brien, Craig, and Peyton ${ }^{14}$ to be a function of the free energy changes at the solid-liquid interfaces and can be expressed by the following equation:

$$
\begin{gathered}
\left(F_{S_{1} V}-F_{S_{1} L}\right)+\left(F_{S_{2} V}-F_{S_{2} L}\right)= \\
-\triangle F^{S}=\gamma_{L V}\left(\operatorname{Cos} \Theta_{1}+\operatorname{Cos} \Theta_{2}\right)
\end{gathered}
$$

Received for publication June 19, 1978.

Accepted for publication November 14, 1978.

This study was supported by a Research Grant, DE 04050, from the National Institute of Dental Research, National Institutes of Health, Bethesda, MD 20205. where $F$ is the free energy, $S_{1}$ and $S_{2}$ are the two solids, $V$ and $L$ are the vapor and liquid, $\gamma_{L V}$ is the surface energy of the liquid, and $\Theta_{1}$ and $\Theta_{2}$ are the contact angles of the liquid against the two solids. If $\triangle \mathrm{F}^{\mathrm{S}}$ is negative, penetration will be spontaneous, and if positive, it will not be spontaneous. Therefore, the preparation of highly hydrophobic surfaces of teeth and restorations could eliminate this capillary penetration.

Fluorocarbon-containing polymers have a low surface energy and are highly hydrophobic. The wettability of fluorinated acrylates and methacrylates and their polymers has been studied by several workers ${ }^{15-18}$ utilizing the concept of critical surface tension which can be determined from contact angle measurements. Their results indicated that fluorine-containing acrylic polymers were difficult to wet with aqueous solution.

The purpose of this study was to formulate a hydrophobic composite restorative system by using a fluorocarbon analog of a methacrylate. The physical, mechanical, and water-related properties of this experimental composite were also evaluated.

Materials and methods.

Formulation of the experimental comTABLE 1

COMPOSITION OF THE EXPERIMENTAL

\begin{tabular}{|c|c|}
\hline Constituents & \% by Weight \\
\hline Octafluoropentylmethacrylate & 18.52 \\
\hline Diacryl $101^{\mathbf{a}}$ & 6.17 \\
\hline Silanated quartz ${ }^{b}$ & 75.00 \\
\hline Camphoro quinone & 0.19 \\
\hline $\begin{array}{l}\mathrm{N}, \mathrm{N} \text {-dimethyl-amino-ethyl } \\
\text { methacrylate }\end{array}$ & 0.12 \\
\hline
\end{tabular}
COMPOSITE

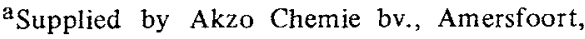
Holland

${ }^{\mathrm{b}}$ Supplied by 3M Company, St: Paul, MN
} 
posite. - The composition of the experimental composite is shown in Table 1. Octafluoropentylmethacrylate is hydrophobic with an advancing contact angle of $100^{\circ}$ on a smooth surface. Diacryl 101 is a difunctional unsaturated methacrylic monomer based on Bisphenol A. It is less hydrophilic and much less viscous than Bis-GMA. The molecular formula of Diacryl 101 is:<smiles>C=C(C)C(=O)OCCOc1ccccc1</smiles><smiles>C=C(C)C(=O)OCCOc1ccc(C)cc1</smiles>

The constituents of the parent resin were mutually dissolved to form a clear solution by carefully balancing the ratio between them. Camphoro quinone and N, N-dimethylaminoethyl-methacrylate were used as accelerators. The experimental composite containing silanated quartz consisted of a single paste, which polymerized by initiation in the presence of blue light.

Method of testing. - The methods of testing described by Craig and co-workers ${ }^{6-7}$ in previous publications were used in this study. In all instances the values reported are means of five replications.
The abrasive wear was determined by the two-body abrasion test used by Powers, Allen, and Craig. ${ }^{19}$ The inclined plane method ${ }^{20}$ was used to determine the contact angles of distilled water on the composite surfaces. A smooth surface of composite prepared against a microscope slide was measured using a cathetometer. A second determination was done after the surface had been finished with a 600 grit silicon carbide paper.

\section{Results.}

Results of physical, mechanical, and water-related properties of the experimental composite are summarized in Tables 2, 3, and 4, respectively. A filled (Adaptic) and an unfilled restorative material (Sevriton) ${ }^{6,7}$ are also listed for comparison. Values of each mean and standard deviation in these tables were calculated from five experimental measurements.

In general, the physical properties of the experimental composite shown in Table 2 are comparable to those of Adaptic, except polymerization contraction, and are higher than those of Sevriton. A high filler content of $77 \%$ by weight and very short setting time of 35 seconds were recorded for the experimental composite. The value of $3.1 \%$ volume contraction is 2.5 times higher than that of Adaptic, but is only $60 \%$ of that of Sevriton. The thermal coefficient of expansion measured between 0 and $60^{\circ} \mathrm{C}$

TABLE 2

PHYSICAL PROPERTIES OF THE EXPERIMENTAL COMPOSITE COMPARED WITH A COMMERCIAL COMPOSITE AND AN UNFILLED RESIN

\begin{tabular}{|c|c|c|c|}
\hline & Adaptic ${ }^{\mathrm{a}}$ & Exp. Comp. & Sevriton ${ }^{b}$ \\
\hline $\begin{array}{l}\text { Inorganic Phase, } \\
\text { wt } \%\end{array}$ & $77.7(0.2)^{\mathrm{c}}$ & $76.2(0.2)$ & - \\
\hline $\begin{array}{l}\text { Working Time, } \\
\text { min. }\end{array}$ & $3.5(0.3)$ & $35 \mathrm{sec}$. & $4.0(0.5)$ \\
\hline $\begin{array}{l}\text { Polymerization } \\
\text { Contraction, Vol. } \%\end{array}$ & $1.3(0.1)$ & $3.1(0.3)$ & $5.2(0.5)$ \\
\hline Density, $\mathrm{g} / \mathrm{cc}$ & $1.98(0.01)$ & $2.16(0.03)$ & $1.12(0.02)$ \\
\hline $\begin{array}{l}\text { Thermal Coefficient } \\
\text { of Expansion, } \times 10^{-6} / \mathrm{C}\end{array}$ & $39.4(1.4)$ & $\begin{array}{l}55.7(5.0)(0-60 \mathrm{C}) \\
53.4(5.4)(\text { at } 37 \mathrm{C})\end{array}$ & $92.0(2.3)$ \\
\hline
\end{tabular}


TABLE 3

MECHANICAL PROPERTIES OF THE EXPERIMENTAL COMPOSITE COMPARED WITH A COMMERCIAL COMPOSITE AND AN UNFILLED RESIN

\begin{tabular}{|c|c|c|c|}
\hline Property & Adaptic ${ }^{\mathbf{a}}$ & Exp. Comp. & Sevriton ${ }^{b}$ \\
\hline $\begin{array}{l}\text { Indentation } \\
\text { depth, mm }\end{array}$ & $0.061(0.002)^{\mathrm{c}}$ & $0.065(0.001)$ & $0.113(0.003)$ \\
\hline Recovery, \% & $74.9(1.7)$ & $66.1(1.5)$ & $74.1(3.5)$ \\
\hline $\begin{array}{l}\text { Compressive } \\
\text { strength, } \mathrm{MPa}\end{array}$ & $237(21)$ & $127(2.9)$ & $71(14)$ \\
\hline $\begin{array}{l}0.1 \% \text { Yield } \\
\text { strength, } \mathrm{MPa}\end{array}$ & $161(9)$ & $80(4.8)$ & $52(7)$ \\
\hline $\begin{array}{l}\text { Modulus of } \\
\text { elasticity, GPa }\end{array}$ & $16.6(0.9)$ & $15.0(1.1)$ & $2.3(0.5)$ \\
\hline $\begin{array}{l}\text { Tensile } \\
\text { strength, } \mathrm{MPa}\end{array}$ & $45.5(2.4)$ & $29.0(1.2)$ & $22.8(0.7)$ \\
\hline $\begin{array}{l}\text { Abrasive wear } \\
\mathrm{mm}^{3} / \mathrm{mm} \times 10^{+4}\end{array}$ & $7.2(0.2)$ & $8.0(0.2)$ & $13.3(1.6)$ \\
\hline
\end{tabular}

TABLE 4

WATER-RELATED PROPERTIES OF THE EXPERIMENTAL COMPOSITE COMPARED WITH A COMMERCIAL COMPOSITE AND AN UNFILLED RESIN

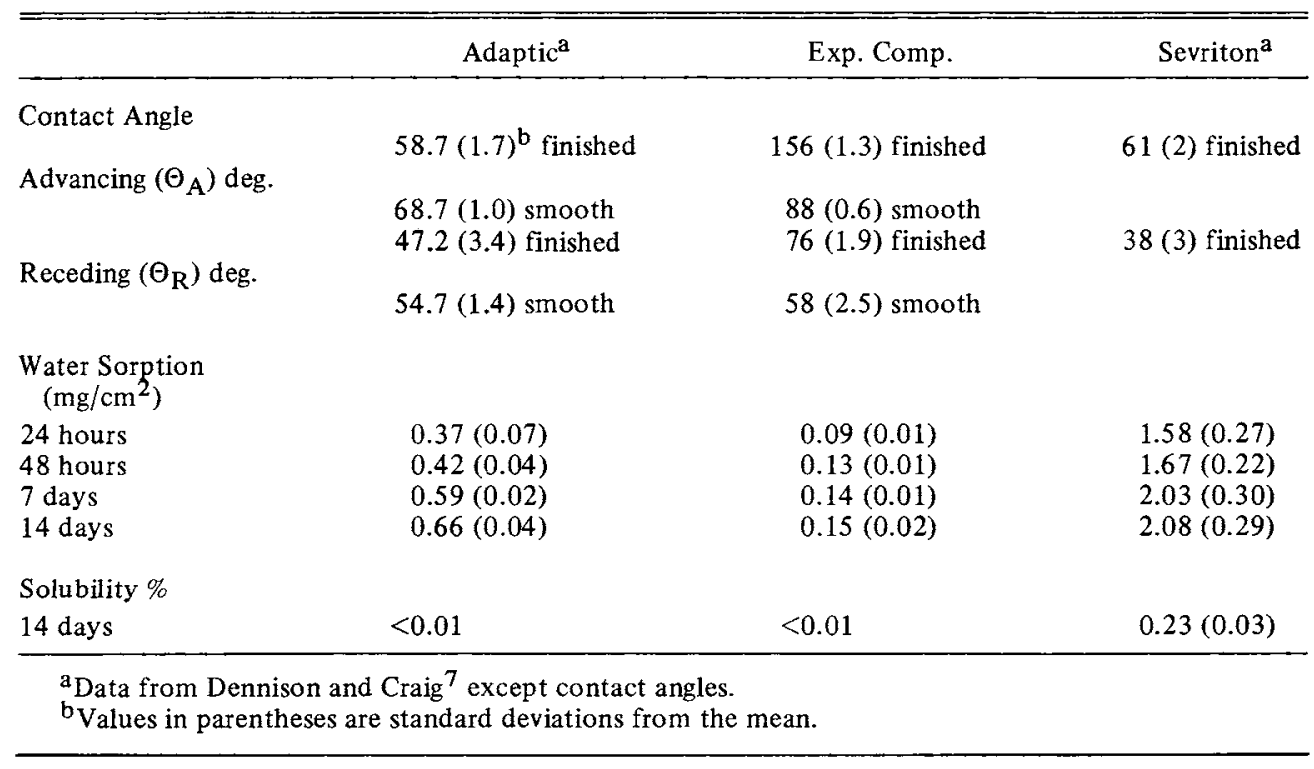

by a thermomechanical analyzer* is relatively higher for the experimental composite

*DuPont Thermal Mechanical Analyzer No. 941, Instrument Division, Wilmington, DE than for Adaptic.

Table 3 shows that the mechanical performance of the experimental composite compares with that of Adaptic and exceeds that of Sevriton. The indentation and the 
modulus obtained from the compression test are about the same for both filled composites. The compressive strength, the $0.1 \%$ yield strength in compression, and the tensile strength from diametral compression tests of the experimental composite are considerably lower than those of Adaptic, ranging from one-half to twothirds. The abrasive wear measured from the two-body test against a 600 grit silicon carbide paper is comparable for both filled materials.

The water-related properties, i.e., contact angles, water sorption, and solubility, are shown in Table 4 . The advancing contact angle of $88^{\circ}$ on a smooth surface is the highest among all. After finishing with a 600 grit paper, the contact angle increased to the very high value of $156^{\circ}$, which is in contrast to a decreasing angle shown in both Adaptic and Sevriton.

The water sorption of the experimental composite measured at one-, two-, seven-, and 14-day periods is much lower than that of Adaptic and Sevriton. It was only $0.15 \mathrm{mg}$ / $\mathrm{cm}^{2}$ at 14 days, and was only one-fourth and one-fifteenth of that of Adaptic and Sevriton. In addition, the experimental composite reached equilibrium very quickly in two days, while the amount of water sorption was still increasing for the other two materials. The solubility of the experimental composite was so low that it was difficult to measure.

\section{Discussion.}

The high polymerization contraction of the experimental composite can be attributed to two causes. First, a relatively high amount of small molecular weight fluoro-methacrylate monomer was used. The attempt to employ a partially polymerized fluoro-methacrylate resulted in a phase separation from the parent resin. Second, the polymerization does not occur until the material is exposed to light. In chemically initiated systems, however, polymerization begins immediately on mixing, and some shrinkage has already taken place by the time of measurement. Therefore, lower polymerization contractions are usually recorded.

The relatively high thermal coefficient of expansion of the experimental composite can be reduced by increasing the filler content. This is possible for the experimental composite because of the very low viscosity of the parent resin. The higher dimensional and thermal changes of the experimental composite could possibly be outweighed by the advantages of its highly hydrophobic character, as discussed later.

In regard to mechanical properties, the high hardness and rigidity of the experimental composite, reflected by the indentation and elastic modulus measurements, were as good as those of Adaptic. The compressive and tensile strengths of the experimental composite are considerably lower than those of Adaptic, but still surpass Sevriton. It is important that, in the attempt to enhance hydrophobicity, other properties are not compromised. These lower values of strength are probably a result of extensive use of fluoro-methacrylate monomers with a fairly low molecular weight, since it requires a great deal of reaction before considerable chain length can be built up. This problem, as well as polymerization contraction, could be resolved by using fluorinated molecules of a large aromatic type similar to Bis-GMA. Nevertheless, the exact clinical relevance of a high tensile and compressive strength has not been shown.

The abrasive wear determined from a two-body test is comparable to that of Adaptic. It is believed by Powers et al. ${ }^{21}$ that ductile failure is preferable to brittle failure in respect to this property. The experimental composite was comparable in abrasive wear to Adaptic in spite of the lower strength; this result may be caused by a lower coefficient of friction of the fluoro-polymer.

The most promising and interesting qualities of the experimental composite are the water-related properties. The water sorption of the experimental composite is much lower than that of Adaptic and Sevriton. This is believed to be associated with hydrophobic polymers. In addition, the experimental composite had only a negligible solubility after 14 days. This result may suggest that the bonding between the polymer and the inorganic phases is strong.

The advancing contact angle of water on a smooth surface is $88^{\circ}$, which is probably the highest in the literature for this type of composite and compares very 
favorably with Adaptic. After finishing with 600 grit paper, the contact angle increased to the very high value of $156^{\circ}$. This result is in contrast to the theory ${ }^{22}$ which predicts a reduction in the measured contact angle by roughening of surfaces with angles below $90^{\circ}$. This is well shown by Adaptic in Table 4 , where the contact angle decreased from $68.7^{\circ}$ to $58.7^{\circ}$. It is believed, therefore, that the bulk of the experimental composite has a contact angle higher than that measured for the smooth surface and is hydrophobic.

According to the equation derived by O'Brien et al., ${ }^{14}$ which was shown previously, a polymer with a contact angle of greater than $130^{\circ}$ would be required in order for $\triangle \mathrm{F}^{\mathrm{S}}$ to be positive, if the contact angle of saliva on dentin is taken to be $50^{\circ}$. Therefore, the experimental composite, having a contact angle of $156^{\circ}$ after finishing, would possibly prevent capillary penetration of oral fluids around restorations. Furthermore, if the walls of the cavity were treated with octafluoropentylmethacrylate, as a varnish, which has a contact angle of $100^{\circ}, \Delta \mathrm{F}^{\mathrm{S}}$ would be more positive, and capillary penetration could be even more difficult. The elimination of fluid penetration should improve the serviceability of the restoration, reduce recurrent caries, and improve dental health. However, the advantages of the experimental composite extend beyond capillary effects to the contoured surface of the restoration. This surface is a low energy surface to which plaque would attach with more difficulty and subsequently be removed with more ease, facilitating oral hygiene regimes. This effect may improve the prognosis for gingival health in the presence of a subgingival composite, which even in competent hands can be associated with a chronic inflammation of the gums.

\section{Conclusions.}

It was possible to produce a hydrophobic composite using a fluorocarbon analog of methacrylate, octafluoropentylmethacrylate, and a bisphenol adduct. The experimental composite was designed as a one-paste system which was polymerized in the presence of blue light. The physical and mechanical properties of the experimental composite were comparable in most instances to a commercial composite, but had higher polymerization contraction and lower compressive and tensile strengths. The profoundly hydrophobic nature of the experimental composite was evident from the high contact angle with water. In addition, the experimental composite had an exceptionally low water sorption value and negligible water solubility.

\section{REFERENCES}

1. BOWEN, R. L.: Properties of a Silica-reinforced Polymer for Dental Restorations, JADA 66:57, 1963.

2. BOWEN, R. L.: Effect of Particle Shape and Size Distribution in a Reinforced Polymer, JADA 69:481, 1964.

3. CHANG, R. W. H.; DAHLMAN, K. E.; and RUBB, J. T.: Properties of a Composite Material for Dental Filling, IADR Progr and Abstr, 44:29, 1965.

4. FREEMAN, F. H.: Composite Restorative Materiais, IADR Progr and Abstr, 48:146, 1969.

5. GOTfRedSEN, C.: Physical Properties of a Plastic Filling Material (Addent), Acta Odontol Scan 27:595, 1969.

6. MACCHI, R. L. and CRAIG, R. G.: Physical and Mechanical Properties of Composite Restorative Materials, JADA 78:328, 1969.

7. DENNISON, J. B. and CRAIG, R. G.: Physical Properties and Finished Surface Texture of Composite Restorative Resins, JADA 85:101. 1972.

8. MCLEAN, J. W. and SHORT, I. G.: Composite Anterior Filling Materials, Brit Dent $J$ 127:9, 1969.

9. PETERSON, E. A.; PHILliPS, R. W.; and SWARTZ, M. L.: A Comparison of the Physical Properties of Four Restorative Resins, JADA 73:1324, 1966.

10. HOLLENBACK, G. M.; VIllaNYI, A. A.; and SHELL, J. S.: A Report on the Physical Properties of a New Restorative Material (Addent), $J S$ Calif Dent Hyg Assoc 34: $250,1966$.

11. GOING, R. E.: Microleakage Around Dental Restorations: A Summarizing Review, JADA 84:1349, 1972.

12. GOING, R. E.; MYERS, H. M.; and PRUSSIN, S. G.: Quantitative Method for Studying Microleakage in vivo and in vitro, $J$ Dent Res 47:1128, 1968.

13. MEYER, J. M.; DENNISON, J. B.; and CRAIG, R. G.: Improved Method of Neutron Activation Analysis for Microleakage Studies, $J$ Dent Res 53:356, 1974.

14. O'BRIEN, W.J.;CRAIG, R. G.; and PEYTON, F. A.: Capillary Penetration Between Dis- 
similar Solids, $J$ Colloid and Interface Sci 26:500, 1968.

15. PITTMAN, A. G.; SHARP, D. L.; and LUDWIG, B. A.: Polymers Derived from Fluorokeytones. II. Wetting Properties of Fluoroalkyl Acrylates and Methacrylates, $J$ Polymer Sci A-1 6:1729, 1968 .

16. ROITMAN, J. N. and PITTMAN, A. G.: Wetting Properties of Acrylic Polymers Containing Perfluoro-t-butyl Side Chains, $J$ Polymer Sci B10:499, 1972.

17. BERNETT, M. $\mathrm{K}$ and ZISMAN, W. A.: Wetting Properties of Acrylic and Methacrylic Polymers Containing Fluorinated Side Chains, J Phys Chem 66:1207, 1962.

18. TAMARIBUCHI, K.: Wettability of Styrene - 2, 2, 3, - Tetrafluoropropyl Methacrylate Copolymers, Am Chem Soc, Polymer Preprints $8: 631,1967$.
19. POWERS, J. M.; ALLEN, L. J.; and CRAIG, R. G.: Two-body Abrasion of Commercial and Experimental Restorative and Coating Resins and an Amalgam, JADA 89:1118, 1974.

20. MACDOUGALL, G. and OCKRENT, C.: Surface Energy Relations in Liquid Solid Systems, Proc Roy Soc, London 180A:151, 1941.

21. POWERS, J. M.; ROBERTS, J. C.; and CRAIG, R. G.: Surface Failure of Commercial and Experimental Restorative Resins, I Dent Res 55:432, 1976.

22. ZISMAN, W. A.: Relations of the Equilibrium Contact Angle to Liquid and Solid Constitution. pp. 1-51. In: Contact Angle, Wettability, and Adhesion, Advances in Chemistry Series 43, Washington, D.C.: American Chemical Society, 1964.

\section{ANNOUNCEMENT \\ Combined \\ First Annual Scientific Session \\ Society For Clinical Trials \\ AND \\ Seventh Annual Symposium For Coordinating Clinical Trials \\ May 6-8, 1980 \\ Philadelphia, Pennsylvania}

The Sessions will focus on the design, organization, management, and analyses of clinical trials.

Abstracts must be received by January 21, 1980 .

For more information write to:

Christian R. Klimt, M.D., Secretary

Society for Clinical Trials, Inc.

600 Wyndhurst Avenue

Baltimore, MD 21210 